\title{
AHP ile Bütünleşik Gri İlişkisel Analiz Yöntemi ile Makine Seçimi: Tarım Makinaları Üretim İşletmesinde Bir Uygulama
}

\author{
Beran GÜLÇIÇEK TOLUN* Ayça TÜMTÜRK ${ }^{* *}$
}

\begin{abstract}
$\ddot{O} Z$
Hız, kalite, maliyet, satış sonrası hizmet gibi çok sayıda kriter açısından farklılık gösteren makineler içinden en uygun makinenin seçimi işletmeler için çok önemli ve karmaşık bir sorundur. Birçok kriterin göz önünde bulundurularak verilmesi gereken bir karar olduğu için etkin bir karar verme sürecine ihtiyaç vardır ve bu konuda çok kriterli karar verme teknikleri çözüm aracı olarak kullanılabilmektedir. Bu çalıșmada birçok kriteri göz önünde bulundurarak makine alması gereken bir işletmenin makine seçim problemine çözüm üretilmesi amaçlanmıştır. Yönetici gözündeki önceliklerinin farklılığ ${ }_{l}$ nedeni ile makine alımında dikkate alınan kriterlerin AHP ile ağırlıklandırılması uygun görülmüş̧ür. İşletme tarafindan belirlenmiş olan farklı alternatifler arasından seçim yapılabilmesi için de Gri İlişkisel Analiz yardımı ile en uygun olanının seçilmesi sağlanmıştır.
\end{abstract}

Anahtar Kelimeler: Çok Kriterli karar verme, AHP, GİA, Makine seçimi

JEL Sinıflandirması: C02, C44, L64

\section{Machine Selection Using Integration of AHP and Grey Relational Analysis: Application in Agricultural Machinery Production Enterprise}

\begin{abstract}
Choosing the most suitable machine among the machines differ in terms of numerous criteria such as speed, quality, cost and after-sales service is a very complicated and important problem for the firms. Since multiple criteria need to be taken into consideration when making decisions, an effective decision-making process is needed, and multi-criteria decision-making techniques can be used as a solution tool. In this study, it is aimed to solve the machine selection problem of an enterprise which should consider many criteria. The criteria considered in the purchasing, weighted with AHP due to the different priorities of criteria in the eyes of the manager. In order to be able to choose from different alternatives, the most appropriate one was provided with the help of Gray Relational Analysis.
\end{abstract}

Key Words: Multi-Criteria Decision Making, AHP, GİA, Machine selection

JEL Classification: C02, C44, L64

\section{GíRiş}

Günümüz ekonomik dünyasında, kar maksimizasyonunu sağlamak, ayrıca rekabette de öne ç1kabilmek için işletmeler yoğun çaba göstermektedirler. Yöneticiler, üretilen ürünlerin kalitesini dolayısıyla da müşteri memnuniyetini

\footnotetext{
* Dr. Öğr. Üyesi, Manisa Celal Bayar Üniversitesi, İ̈BF, İşletme Bölümü, berangulcicek@yahoo.com, ORCID Bilgisi: 0000-0002-7552-2351

** Dr. Öğr. Üyesi, Manisa Celal Bayar Üniversitesi, İIBF, İşletme Bölümü, aycademirbilek@hotmail.com ORCID Bilgisi:0000-0002-7576-2953
} 
artıracak ve maliyetleri azaltıcı uygulamalar bulmak zorundadırlar. $\mathrm{Bu}$ amaçlar doğrultusunda da en iyi çözümü sunacak yatırımları seçmek durumundadırlar.

Mal ve hizmet üreten işletmeler için üretim sisteminin performansını doğrudan etkileyecek karar verme problemlerinden biri üretim sürecinde kullanılacak makinelerin seçimidir. Üretim hızı, üretilen ürünün kalitesi, maliyetler ve verimlilik önemli derecede üretim sürecinde kullanılan makinelerin seçim kararının doğruluğuna bağlıdır. Yoğun rekabetin yaşandığı günümüzde sürekli değişen koşullara uyum sağlayabilmek ve fark yaratabilmek için karar vericilerin birçok veriyi analiz edip çok sayıda faktörü dikkate alarak etkin ve hızlı bir şekilde karar vermeleri gerekmektedir. İşletme yöneticileri ve operatörlerin makine seçimine ilişkin nicel maliyet kalemiyle birlikte, diğer nitel performans ölçütlerini birlikte değerlendirmesi gerekmektedir (Çakır ve Akar, 2017:208). Makine seçimine yönelik karar verme sürecinde göz önünde bulundurulan kriterlerin birbiri üzerindeki etkileşimleri ve kriterlerin bağımlılık dereceleri karar verme sürecinde önemlidir.

Karar verme süreci problemin tanımı, kriterlerin ve alternatiflerin belirlenmesi, en iyi alternatifin seçimi ve sonuçlarının değerlendirilmesini içeren karmaşık bir süreçtir. Karar sürecini kontrol altında tutmak, karar sürecinin modellenmesi ve analizine imkân veren, karar sürecine etki edebilecek tüm bilgilerin yeterli şekilde değerlendirilmesini sağlayacak sistematik yaklaşımlar sunulması amacıyla çok kriterli karar verme (ÇKKV) metotları geliştirilmiştir (Şeker ve Yurdakul, 2014:590). Makine seçim kararı çok sayıda kriteri göz önünde bulundurarak verilmesi gereken bir karar olarak düşünülmesi gerektiği için ÇKKV problemi olarak düşünülmelidir.

Bu çalışmada Analitik Hiyerarşi Süreci (AHP) ve Gri İlişkisel Analiz (GİA) yöntemleri birlikte kullanılarak çiftlik ekipmanları üreten ve alıp satan bir işletme için makine seçimi ele alınmıştır. Makine alımında yöneticinin önceliklerinin dikkate alınması gerekliliği düşünüldügüüde, makine alımında dikkate alınan kriterleri ağırlıklandırmanın daha gerçekçi çözümler üreteceği düşünülmektedir ve bu nedenle kriterlerin ağırlıklandırılmasında Analitik Hiyerarşi Prosesi, Makinenin satın alınabileceği firmaların sıralanması için ise Gri İlişkisel Analiz (GİA) kullanılmıştır. Çalışmanın birinci bölümünde literatür taramasına yer verilmiş, ikinci bölümde uygulamada kullanılan yöntemler anlatılmış, üçüncü bölümde AHP ile bütünleşik GİA'nın bir üretim işletmesinin makine alım kararı için kullanıldığı uygulama çalışması ve bulgulara, dördüncü bölümde de sonuç ve önerilere yer verilmiştir.

\section{LITERATÜR TARAMASI}

Literatürde son yıllarda AHP ve GİA yöntemlerinin çok çeşitli alanlarda birlikte kullanıldığı görülmektedir. Çalışmanın bu bölümünde çok kriterli karar verme tekniklerinden AHP ve GİA'nın entegre olarak kullanıldı̆̆ problemleri, kriterleri ve alternatifleri içeren çalışmalara yer verilmiştir.

Pophali vd., 2011 yılındaki çalışmalarında atık su arıtma alternatifleri arasından seçim yapmak için bütünleşik AHP-GİA yöntemini kullanmışlardır. Güney Hindistan'da 7 tabakhane ve onların atık su arıtma tesisleri ekonomik, 
teknik ve idari olmak üzere 3 kriter ve bu kriterlerin alt kriterlerine göre değerlendirilmiştir. AHP sonrasında GİA kullanılmış ve buna göre atık su artırma alternatifleri arasında gri ilişki katsayısı en yüksek olan 4. alternatif seçilmiştir.

Samvedi vd., (2012), bir imalathane için en uygun tezgâhı seçmek amacıyla, AHP ve GİA yöntemlerini birlikte kullanmışlardır. Maliyet, esneklik, verimlilik, güvenlik gibi kriterler AHP yöntemiyle ağılıklandırıldıktan sonra en uygun tezgâha GİA yöntemiyle karar verilmiştir.

Tayyar vd., (2014), Borsa İstanbul'a kayıtlı bilişim ve teknoloji sektöründe faaliyet gösteren işletmelerin performanslarının değerlendirilmesinde AHP ve GİA yöntemlerini birlikte kullanmışlardır. AHP ile kriterler ağırlıklandırılarak ağırlı̆ğ en yüksek olan kriter karlılık olarak belirlenmiş ve GİA yöntemi ile de işletmeler performanslarına göre sıralanmıştır.

Wang vd (2015), GİA ve AHP'ye göre mısır briketleme yakıt sistemi için matematiksel bir model oluşturmuştur. $\mathrm{Bu}$ model, ekonomi, temizlik, çevre koruma, üretim kapasitesi, ürün kalitesi ve üretim istikrarı kriterlerinin altında, toz içeriği, kurutma kapasitesi gibi alt kriterleri içeren toplam 6 ana, 20 alt kritere göre değerlendirme yapmıştır. Hiyerarşiyi etkileyen en önemli faktörler ise duyarlılık analizi kullanılarak analiz edilmiştir. mısır briketleme yakıt sistemi kurutma makinesi, doğrama makinesi, briketleme makinesi, soğutma makinesinden oluşmaktadır. Çalışmada bu makinelerin farklı kombinasyonlarından oluşan 5 farklı projeden optimum olan proje seçilmiştir.

Senger ve Albayrak 2016 yılında yayımlanan makalelerinde çok kriterli karar verme tekniklerinden AHP ve GIA yöntemini kullanarak mobilya sektöründeki bir işletmenin mavi yakalı personellerinin performanslarını değerlendirmişlerdir. Firma yöneticileri ve personel değerlendirmesi yapan uzmanlarla 8 kriter belirlenmiş, AHP sonuçlarına göre en önemli kriter yapılan işin kalitesi olarak ortaya konmuştur. Toplam 36 mavi yakalı bu kriterlere göre değerlendirilmiş ve GİA sonuçlarına göre sıralanmıştır.

Arslan vd. (2017), yaptıkları çalışmada, tekstil alanında faaliyet gösteren 14 işletmeyi finansal performanslarına göre sıralayabilmek için AHP ve GİA yöntemlerini bir arada kullanmışlar, AHP ile 33 kriter ağırlıklandırıldıktan sonra, GİA yöntemiyle de işletmeleri performanslarına göre sıralamışlardır.

Organ ve Yalçın (2017), çalışmalarında bir tekstil firması için en iyi ısıtma kaynağını belirleyebilmek için; maliyet, çevre dostu olma, ulaşılabilirlik gibi kriterleri AHP ile ağırlıklandırdıktan sonra farklı alternatifler (kömür, doğalgaz, dizel, elektrik) arasından en iyisini GİA yöntemiyle doğal gaz olarak belirlemişlerdir.

Ecemiş ve Yaykaşlı (2018)'nın çalışmalarında, endüstriyel mutfak sektöründe faaliyet gösteren ithalatçı bir firmanın tedarikçi seçiminde kullanılan kriterler AHP yöntemiyle ağırlıklandırılmış ve kalite uygunluğu, teknik ve tasarım kapasitesi, üretim tesisleri/yetenekleri en önemli üç kriter olarak belirlendikten sonra, 13 tedarikçi firma GİA yöntemiyle değerlendirilmiştir.

Korucuk 2018 yılındaki çalışmasında İstanbul'da faaliyet gösteren ve soğuk zincir taşımacılı̆̆ yapan 4 3PL firmasını AHP ve GİA yöntemlerini 
kullanarak kıyaslamıştır. Soğuk zinciri taşımacılığı alanında uzman toplam 25 uzmanın görüşü neticesinde 4 ana kriter ve 20 alt kriter belirlenmiştir. Kriter ağırlıklarını belirlemek için AHP yöntemi, 4 firmayı kıyaslamak için AHP ağırlıklarını kullanan GİA yöntemi kullanılmıştır.

İpek ve Şahin (2018), AHP ve GİA yöntemlerini kullanarak Isparta'da yaşayan 4 kişilik bir aile için konut seçimi problemini çözmüşlerdir. Toplam 6 ana kriter ve 21 alt kriterin belirlendiği çalışmada AHP sonuçlarına göre en önemli kriter 0,42 değeri ile konutun fiyatı olarak bulunmuştur. Ailenin belirlediği 15 lokasyon GİA'ya tabi tutulmuş ve AHP yönteminden elde edilen kriter ağıllıkları kullanılmıştır.

Şahin ve Aydemir 2019 yılında yaptıkları çalışmalarında akıllı telefon seçimi için dikkate alınan müşteri gereksinimlerini literatürdeki çalışmalardan belirlemişlerdir. Bu müşteri gereksinimlerini teknik karakteristiklere dönüştürerek toplam 8 satış uzmanından pazar payı en yüksek beş akıllı telefonu 1-9 ölçeğinde değerlendirmeleri istenmiştir. Bu skala kullanılarak AHP ve GİA yöntemleri uygulanmış ve "ekran" teknik karakteristiğinin en önemli kriter olduğu sonucuna ulaşılmıştır.

\section{YÖNTEM}

\section{A. Analitik Hiyerarşi Prosesi (AHP)}

Analitik Hiyerarşi Prosesi, 1977 y1lında Thomas L. Satty tarafindan geliştirilmiş çok kriterli karar verme tekniklerinden biridir. AHP metodolojisini kullanmanın en önemli avantajlarından biri esnekliği ve farklı problem tiplerine uygulanabilirliğidir. Ayrıca diğer çok kriterli karar verme teknikleri ile kıyaslandığında daha kolay uygulama adımlarına sahiptir (Said ve Harputlugil, 2019:37).

Analitik Hiyerarşi Prosesi (AHP), karar verme sürecinde çeşitli kriterlere göre değerlendirilen alternatiflerden en iyisini seçmek için tasarlanmıştır. Karar verme sürecinde süreci basitleştirmek ve önceliklerin belirlenebilmesi için ikili karşılaştırmalar yapılmaktadır (Pancaroğlu, 2018:20).

Karar verme probleminde yer alan alternatiflerin belirlenmesinden sonraki adımda karşılaştırma matrisinin hazırlanması gerekmektedir. n sayıda kriterin bulunduğu bir problemde $\mathrm{n}(\mathrm{n}-1) / 2$ adet karşılaştırma yaparak karşlaştırma matrisi oluşturulacaktır. Tüm kriterler ikili olarak karşılaştırılırken Tablo 1'de gösterilen Satty'nin 1-9 ölçeği kullanılmaktadır. Karşılaştırma matrisinde, i'inci kriter ile j'inci kriterin önem derecesinin $a_{i j}$ ile gösterilmesi durumunda karşılaştırma matrisi aşağıda gösterilen A matrisi gibi yazılmış olacaktır.

$$
\mathbf{A}=\left[\begin{array}{cccc}
a_{11} & a_{12} & \cdot & a_{1 n} \\
a_{21} & a_{22} & \cdot & a_{2 n} \\
\cdot & \cdot & \cdot & \cdot \\
a_{n 1} & a_{n 2} & \cdot & a_{n n}
\end{array}\right]
$$


Tablo 1. Saaty Ölçeği Değerleri

\begin{tabular}{|l|l|}
\hline $\begin{array}{l}\text { Önem } \\
\text { Değerleri }\end{array}$ & Değer Tanımları \\
\hline 1 & Her iki faktörün eşit öneme sahip olması durumu \\
\hline 3 & 1. Faktörün 2. faktörden daha önemli olması durumu \\
\hline 5 & 1. Faktörün 2. faktörden çok önemli olması durumu \\
\hline 7 & 1. Faktörün 2. faktöre nazaran çok güçlü bir öneme sahip olması durumu \\
\hline 9 & 1. Faktörün 2. faktöre nazaran mutlak üstün bir öneme sahip olması durumu \\
\hline $2,4,6,8$ & Ara değerler \\
\hline
\end{tabular}

Kaynak:Saaty 1986:843

Karşılaştırma matrisinin oluşturulmasından sonraki adımda ise, aşağıda yer alan formülasyon kullanılarak, her bir sütun değerinin ilgili sütun toplamına bölünmesiyle B normalizasyon matrisi oluşturulur.

$$
\begin{aligned}
& b_{i j}=\frac{a_{i j}}{\sum_{i=1}^{n} a_{i j}} \\
& \mathrm{~B}=\left[\begin{array}{cccc}
b_{11} & b_{12} & \cdot & b_{1 n} \\
b_{21} & b_{22} & \cdot & b_{2 n} \\
\cdot & \cdot & \cdot & \cdot \\
b_{n 1} & b_{n 2} & \cdot & b_{n n}
\end{array}\right]
\end{aligned}
$$

B matrisinden yararlanarak kriterlerin önem düzeylerinin belirlenebilmesi için B matrisinin satır bileşenlerinin aritmetik ortalaması alınır ve W sütun vektörü elde edilir.

$$
W=\left[\begin{array}{c}
w_{1} \\
w_{2} \\
\cdot \\
w_{n}
\end{array}\right]
$$

AHP sonuçlarının gerçekçiliği karar vericinin yapmış olduğu ikili karşılaştırmaların tutarlılığına bağlı olacağı için AHP bu tutarlılığın ölçülebilmesini sağlayacak bir tutarlılık analizi önermektedir. Tutarlılık analizi sonucunda elde edilecek olan tutarlılık oranı 0,10'dan küçük ise ikili karşılaştırma matrisinin tutarlılı̆̆ından bahsedilebilecek, aksi durumda karşılaştırma matrisinin tekrar oluşturulması gerekecektir. Tutarlılık Analizinin aşamaları aşağıdaki gibidir:

$\lambda$ ' nın hesaplanması için öncelikle A karşılaştırma matrisi ile W öncelik vektörünün matris çarpımından D sütun vektörü elde edilir:

$$
\mathrm{D}=\left[\begin{array}{cccc}
a_{11} & a_{12} & \cdot & a_{1 n} \\
a_{21} & a_{22} & \cdot & a_{2 n} \\
\cdot & \cdot & \cdot & \cdot \\
a_{n 1} & a_{n 2} & \cdot & a_{n n}
\end{array}\right] \times\left[\begin{array}{c}
w_{1} \\
w_{2} \\
\cdot w_{3} \\
w_{4}
\end{array}\right]
$$


D matrisi ile W sütun vektörünün karş1lıklı elemanlarının bölünmesi ile her bir değerlendirme faktörüne ilişkin temel değer (E) elde edilir. Bu değerlerin aritmetik ortalaması ise karşılaştırmaya ilişkin temel değeri $(\lambda)$ verir:

$$
\begin{aligned}
& E_{i}=\frac{d_{i}}{w_{i}} \quad(i=1,2, \ldots, n) \\
& \lambda=\frac{\sum_{i=1}^{n} E_{i}}{n}
\end{aligned}
$$

$\lambda$ hesaplandıktan sonra Tutarlılık Göstergesi (CI), aşağıda yer alan formülünden yararlanarak hesaplanabilir.

$$
C I=\frac{\lambda-n}{n-1}
$$

Son aşamada ise CI, Random İndex (RI) olarak adlandırılan standart düzeltme değerine bölünerek CR(Tutarlılık oranı) elde edilir. Burada Tablo 2'de gösterilen RI (Random Index) rasgelelik indeksidir. Rasgelelik indeksi $n$ değerine (karşlaştırma matrisinin boyutuna) göre değişir.

Tablo 2. Random Index Değerleri

\begin{tabular}{|c|c|c|c|c|c|c|c|c|c|c|c|c|c|}
\hline $\mathrm{N}$ & 3 & 4 & 5 & 6 & 7 & 8 & 9 & 10 & 11 & 12 & 13 & 14 & 15 \\
& & & & & & & & & & & & & \\
\hline $\mathrm{RI}$ & $\mathbf{0 , 5 8}$ & $\mathbf{0 , 9 0}$ & $\mathbf{1 , 1 2}$ & $\mathbf{1 , 2 4}$ & $\mathbf{1 , 3 2}$ & $\mathbf{1 , 4 1}$ & $\mathbf{1 , 4 5}$ & $\mathbf{1 , 4 9}$ & $\mathbf{1 , 5 1}$ & $\mathbf{1 , 4 8}$ & $\mathbf{1 , 5 6}$ & $\mathbf{1 , 5 7}$ & $\mathbf{1 , 5 9}$ \\
\hline
\end{tabular}

Kaynak: Saaty, 2005.

\section{B. Gri İlişkisel Analiz}

Gri İlişkisel Analiz (GİA), Gri Sistem Teorisinin (GST) bir parçasıdır. Çeşitli alanlarda uygulama imkânı bulan GST, 1982 yılında Deng tarafindan geliştirilmiştir. GST, belirsizlik ortamında çalışan metotlardan biridir ve eksik, zayıf ya da kesin olmayan bilgi içeren sistemlerin matematiksel analizinde kullanılır (Kuo, vd, 2008:81). GST'de bilginin derecesine göre, eğer sistem bilgisi tamamen biliniyorsa beyaz sistem, eğer bilinmiyorsa siyah sistem olarak adlandırılır. Bilginin bir kısmının bilindiği sistemlere ise gri sistemler denir ( $\mathrm{Li}$, vd., 2007: 574). GİA, GST'nin en çok kullanılan ve en dinamik bileşenidir. GİA, verilen bilgiler az olsa bile, seriler arasındaki ilişkileri veya sistem davranışını analiz etmek için basit bir şema sağlar. GİA, sistemin gelişim trendini etkileyen faktörlerin nicel karşılaştırmalı analizidir. Bu analiz yöntemi, ilişkinin derecesine bağlı olarak analize sokulan iki dizi arasındaki benzerlik veya fark derecesini ölçen bir etki değerlendirme modeli sunar (Lee, Lin, 2011: 2552). Bu yönüyle finanstan turizm sektörüne, insan kaynaklarından üretime, kısacası çok kriterli karar vermenin bulunduğu her ortamda kullanılır. GİA bulanık mantıkta da kullanılan dilsel değişkenler (linguistic variables) denilen çok az, az, orta, yüksek, çok yüksek gibi betimlemeler ile alternatifler skor aldıysa, gri sayıları kullanır (Türkbey, 2003: 82). Örnek gri sayı dönüşümü Tablo 3'de verilmiştir. 
Tablo 3. Sübjektif Kriterlerin Gri Sayı Karşılığ1

\begin{tabular}{ll} 
Değerlendirme & Gri Sayı Karşılı̆̆ 1 \\
\hline Çok Zayıf & {$[\mathbf{0 , 1 0 ]}$} \\
\hline Zayıf & {$[\mathbf{1 0 , 3 0 ]}$} \\
\hline Orta Derecede Zayıf & {$[\mathbf{3 0 , 4 0 ]}$} \\
\hline Ortalama & {$[\mathbf{4 0 , 5 0 ]}$} \\
\hline Orta Derecede İyi & {$[\mathbf{5 0 , 6 0}]$} \\
\hline İyi & {$[\mathbf{6 0 , 9 0 ]}$} \\
\hline Çok İyi & {$[\mathbf{9 0 , 1 0 0}]$}
\end{tabular}

Kaynak: Li, vd., 2007: 576

GİA yöntemi toplam 6 adımdan oluşur (Senger, , 2016: 242):

\section{Alternatif ve kriterlerin belirlenmesi}

$\mathrm{Bu}$ aşamada $\mathrm{m}$ kadar alternatif $(\mathrm{i}=1,2, \ldots, \mathrm{m})$ ve $\mathrm{n}$ kadar $\operatorname{kriter}(\mathrm{j}=1,2, \ldots \mathrm{n})$ belirlenerek mxn'lik karar matrisi oluşturulur.

$\left[\begin{array}{c}x_{11}, x_{12}, x_{13}, \ldots, x_{1 n} \\ x_{21}, x_{22}, x_{23} \ldots, x_{2 n} \\ \ldots \ldots \ldots \ldots \ldots \ldots \ldots \ldots \\ \ldots \ldots \ldots \ldots . . . . . . . . . . \\ x_{m 1}, x_{m 2}, x_{m 3} \ldots, x_{m n}\end{array}\right]$

2. Referans serisinin oluşturulması

Serilerin en küçük veya en büyük değerlerinin bulunarak kıyaslama sağlamak için kullanılacak olan serinin oluşturulması aşamasıdır. Bazen karar vericiler en yüksek ya da en düşük değeri almaktan ziyade kendileri de referans değerler belirleyebilirler, ancak bu yöntem pek tercih edilmemektedir (Kuo, vd., 2008: 82).

$x_{0}=\left[x_{01}, x_{02}, x_{03} \ldots, x_{0 \mathrm{j}}, \ldots, x_{0 \mathrm{n}}\right]$

Örneğin, $x_{0 \mathrm{j}}$, j. Kritere göre alternatiflerin aldığı en iyi değeri (en küçük veya en büyük) gösterir.

\section{Normalizasyon işlemi}

$\mathrm{Bu}$ aşamaya standartlaştırma aşaması da denir. Burada büyük değerin daha iyi (5), küçük değerin daha iyi (6) ve optimal değerin daha iyi (7) olma durumuna göre üç farklı denklemden yararlanılabilir.

$$
\begin{aligned}
x_{i}^{*} & =\frac{x_{i j}-\min _{j} x_{i j}}{\max _{j} x_{i j}-\min _{j} x_{i j}} \\
x_{i}^{*} & =\frac{\max _{j} x_{i j}-x_{i j}}{\max _{j} x_{i j}-\min _{j} x_{i j}} \\
x_{i}^{*} & =\frac{x_{i j}-x_{0 j}}{\min _{j} x_{i j}-x_{0 j}}
\end{aligned}
$$

Burada:

$x_{i j}: \quad$ i. alternatif için j. kriter değeri

$\min _{j} x_{i j}:$ j. kriter için en küçük değer

$\max _{j} x_{i j}:$ j. kriter için en büyük değer 
$x_{0 j}: \quad$ j. kriter için referans seri değeri

olarak tanımlanabilir.

Normalizasyon işleminin ardından normalizasyon matrisi elde edilir. $\mathrm{Bu}$ matriste tüm değerler 0 ve 1 arasında değerler alır. Bir alternatifin bir kriter için aldığ1 değerin 1'e yaklaşması iyi 0'a yakın olması ise iyi olmadığı anlamına gelmektedir.

$\left[\begin{array}{c}x_{11}^{*}, x_{12}^{*}, x_{13}^{*}, \ldots, x_{1 n}^{*} \\ x_{21}^{*}, x_{22}^{*}, x_{23}^{*}, \ldots, x_{2 n}^{*} \\ \ldots \ldots \ldots \ldots \ldots \ldots \ldots \ldots \\ x_{m 1}^{*}, x_{m 2}^{*}, x_{m 3}^{*}, \ldots, x_{m n}^{*}\end{array}\right]$

\section{Mutlak değer matrisinin oluşturulması}

Referans seriden normalizasyon matrisindeki değerlerin çıkarılması ile elde edilen matristir.

$\Delta_{i j}=\left|x_{0 j}^{*}-x_{i j}^{*}\right|$
$\left[\begin{array}{c}\Delta_{11}, \Delta_{12}, \Delta_{13}, \ldots, \Delta_{1 n} \\ \Delta_{21}, \Delta_{22}, \Delta_{23}, \ldots, \Delta_{2 n} \\ \ldots \ldots \ldots \ldots \ldots \ldots \ldots \ldots \\ \Delta_{m 1}, \Delta_{m 2}, \Delta_{m 3}, \ldots, \Delta_{m n}\end{array}\right]$

\section{Gri ilişkisel katsayı matrisinin oluşturulması}

Gri ilişkisel katsayı, $\gamma_{i j}$, matrisinin oluşturulması için aşağıdaki denklem kullanılır.

$\gamma_{i j}=\frac{\Delta_{\min }+\zeta \Delta_{\max }}{\Delta_{i j}+\zeta \Delta_{\max }}$

Burada $\Delta_{\min }$ ve $\Delta_{\max }$ bir önceki aşamada oluşturulan mutlak fark matrisindeki en küçük ve en büyük değerlerdir. $\zeta$ ise ayırıcı katsayı olarak geçer. $\mathrm{Bu}$ katsayı 0 ile 1 arasında değerler alır. 1'e yakın seçilirse ayırıcılık üst seviyeye yaklaşmış olur. 0'a yakın seçildiğinde ise ayırıcılık alt seviyeye yaklaşmış olur. Literatürde bu katsayı 0,5 olarak genel kabul görmüştür (Xiao, vd., 2012: 1994).

\section{Gri ilişkisel derecelerin hesaplanması}

Gri ilişkisel dereceler hesaplanırken, gri ilişkisel katsayılar kriter ağırlıkları ile çarpılır. Burada iki durum söz konusudur. Eğer kriter ağırlıkları eşit ise denklem (10), eğer karar vericinin belirlediği farklı kriter ağırlıkları $\left(\mathrm{w}_{\mathrm{i}}\right)$ varsa denklem (11) kullanılır.

$\Gamma_{\mathrm{i}}=\frac{1}{n} \sum_{j=1}^{n} \gamma_{i j}$

$\Gamma_{\mathrm{i}}=\sum_{j=1}^{n} w_{i} \gamma_{i j}$

III. UYGULAMA VE BULGULAR

$\mathrm{Bu}$ çalışmada verilerin elde edildiği ve makine alım problemine çözüm bulunmaya çalışılan işletme İzmir'de çiftlik ekipmanları ve tarım makineleri alıp satan ve üreten bir işletmedir. Çalışmada yöneticilerin bir makine alımında göz önünde bulundurdukları kriterler belirlenerek alternatifler arasından en uygun makinenin seçilmesinin sağlanması amaçlanmaktadır. Analiz sırasındaki 
değerlendirmeler 4 kişilik bir takım oluşturularak, uzman görüşleri alınarak yapılmıştır. Uygulamanın ilk aşamasında yöneticilerin görüşleri alınarak makine alımında göz önünde bulundurulan kriterler Tablo 4'te görüldüğü gibi belirlenmiştir.

Tablo 4. Makine Alımında Kriterler

\begin{tabular}{l|l} 
1.KRITER (K1) & Dozaşlama süresi \\
2.KRITER(K2) & Hareket kabiliyeti \\
3.KRITER(K3) & Motor gücü \\
4.KRITER (K4) & Mama yapma süresi \\
5.KRiTER(K5) & Yıama sistemi \\
6.KRITER(K6) & Pastörize etme süresi \\
7.KRiTER (K7) & Fiyat \\
8.KRiTER(K8) & Satış sonrası hizmet \\
9.KRITER(K9) & Ürün teslim süresi \\
10.KRITER (K10) & Dil seçeneği
\end{tabular}

Yöneticilerin görüşü alınarak belirlenen her bir kriterin yöneticilerin gözündeki değerinin farklı olması sebebi ile Gri İlişkisel Analiz ile en iyi satın alma alternatifinin belirlenmesi aşamasından önce AHP ile her bir kriterin önem düzeylerinin belirlenmesinin daha gerçekçi sonuçlar ortaya çıkaracağ düşünülmüştür.

\section{A. AHP ile Kriterlerin A ğırlıklarının Belirlenmesi}

AHP'nin ikinci adımında Saaty'nin karşılaştırma ölçeği kullanılarak belirlenen kriterler için karşılaştırma matrisi Tablo 5'de görüldüğü gibi oluşturulmuştur.

Tablo 5. İkili Karşılaştırma Matrisi

\begin{tabular}{|c|c|c|c|c|c|c|c|c|c|c|}
\hline Kriterler & K1 & K2 & K3 & K4 & K5 & $\mathrm{K6}$ & K7 & K8 & K9 & K10 \\
\hline K1 & 1,00 & 0,33 & 0,50 & 2,00 & 0,20 & 0,17 & 3,00 & 0,25 & 4,00 & 5,00 \\
\hline K2 & 3,00 & 1,00 & 2,00 & 4,00 & 0,33 & 0,25 & 5,00 & 0,50 & 6,00 & 7,00 \\
\hline K3 & 2,00 & 0,50 & 1,00 & 3,00 & 0,25 & 0,20 & 4,00 & 0,33 & 5,00 & 6,00 \\
\hline K4 & 0,50 & 0,25 & 0,33 & 1,00 & 0,17 & 0,14 & 2,00 & 0,20 & 3,00 & 4,00 \\
\hline K5 & 5,00 & 3,00 & 4,00 & 6,00 & 1,00 & 0,50 & 7,00 & 2,00 & 8,00 & 9,00 \\
\hline K6 & 6,00 & 4,00 & 5,00 & 7,00 & 2,00 & 1,00 & 8,00 & 3,00 & 9,00 & 9,00 \\
\hline K7 & 0,33 & 0,20 & 0,25 & 0,50 & 0,14 & 0,13 & 1,00 & 0,17 & 2,00 & 3,00 \\
\hline K8 & 4,00 & 2,00 & 3,00 & 5,00 & 0,50 & 0,33 & 6,00 & 1,00 & 7,00 & 8,00 \\
\hline K9 & 0,25 & 0,17 & 0,20 & 0,33 & 0,13 & 0,11 & 0,50 & 0,14 & 1,00 & 2,00 \\
\hline K10 & 0,20 & 0,14 & 0,17 & 0,25 & 0,11 & 0,11 & 0,33 & 0,13 & 0,50 & 1,00 \\
\hline
\end{tabular}

sonrasında her bir hücre değerinin sütun toplamına bölünmesi ile normalizasyon matrisi ve satır toplamlarının aritmetik ortalaması alınarak elde edilen kriter ağırlıkları Tablo 6' da görüldüğü gibi elde edilmiştir.

Tablo 6. Normalizasyon Matrisi

\begin{tabular}{|c|l|l|l|l|l|l|l|l|l|l|r|}
\hline Kriterler & K1 & K2 & K3 & K4 & K5 & K6 & K7 & K8 & K9 & K10 & W(Ağırlıklar) \\
\hline K1 & 0,04 & 0,03 & 0,03 & 0,07 & 0,04 & 0,06 & 0,08 & 0,03 & 0,09 & 0,09 & 0,06 \\
\hline K2 & 0,13 & 0,09 & 0,12 & 0,14 & 0,07 & 0,09 & 0,14 & 0,06 & 0,13 & 0,13 & 0,11 \\
\hline K3 & 0,09 & 0,04 & 0,06 & 0,10 & 0,05 & 0,07 & 0,11 & 0,04 & 0,11 & 0,11 & 0,08 \\
\hline K4 & 0,02 & 0,02 & 0,02 & 0,03 & 0,03 & 0,05 & 0,05 & 0,03 & 0,07 & 0,07 & 0,04 \\
\hline K5 & 0,22 & 0,26 & 0,24 & 0,21 & 0,21 & 0,17 & 0,19 & 0,26 & 0,18 & 0,17 & 0,21 \\
\hline K6 & 0,27 & 0,35 & 0,30 & 0,24 & 0,41 & 0,34 & 0,22 & 0,39 & 0,20 & 0,17 & 0,29 \\
\hline K7 & 0,01 & 0,02 & 0,02 & 0,02 & 0,03 & 0,04 & 0,03 & 0,02 & 0,04 & 0,06 & 0,03 \\
\hline K8 & 0,18 & 0,17 & 0,18 & 0,17 & 0,10 & 0,11 & 0,16 & 0,13 & 0,15 & 0,15 & 0,15 \\
\hline K9 & 0,01 & 0,01 & 0,01 & 0,01 & 0,03 & 0,04 & 0,01 & 0,02 & 0,02 & 0,04 & 0,02 \\
\hline K10 & 0,01 & 0,01 & 0,01 & 0,01 & 0,02 & 0,04 & 0,01 & 0,02 & 0,01 & 0,02 & 0,02 \\
\hline
\end{tabular}


Tablo 6' da görüldüğü gibi altınc1 kriter olan makinenin pastörize etme süresi birinci sırada, beşinci kriter olan yıkama sistemi ikinci sırada yer alırken, üçüncü en yüksek ağırlığa sahip olan kriter ise satış sonrası hizmet olarak belirlenmiştir. Ağırlıkların belirlenmesi sonrasında yöneticilerin ikili karşılaştırmalar sırasında tutarlı cevaplar verip vermediklerini anlamak üzere tutarlılık analizi yapılmıştır. Tutarlılık analizi sırasında $\lambda$ değeri 10,56 olarak bulunmuştur. CI değerinin 0,06 bulunması sonrasında hesaplanan tutarlılık oranının 0,04 yani 0,10 'dan küçük çıkması yapılan ikili karşılaştırmalarda tutarlılığın sağlandığını göstermiştir.

$$
\begin{aligned}
& C I=\frac{\lambda-n}{n-1}=\frac{10,56-10}{9}=0,06 \\
& \mathrm{CR}=\frac{C I}{R I}=\frac{0,06}{1,49}=0,04<0,10
\end{aligned}
$$

\section{B. AHP ile Bütünleşik Gri İlişkisel Analiz Yardımıyla En Uygun Alternatifin Seçilmesi}

Karar matrisi oluşturulurken makine alımının yapılacağ alternatiflerinin 10 kritere göre değerlendirmesini yapmak gerekmiştir. Bu amaçla işletmede çalışan karar verici pozisyonundaki iki uzman ve iki akademisyen ile değerlendirme yapılmıştır. Alternatiflerin kriterlere göre değerlendirilmesinde kullanılan ifadeler ve kisaltmaları Tablo 7'de, uzmanlardan alınan değerlendirmeler sonucu oluşturulan karar matrisi Tablo 8'de sunulmuştur.

Tablo 7. Değerlendirmede Kullanılan İfadeler ve Kısaltmaları

\begin{tabular}{l|c}
\multicolumn{1}{c}{ DEĞERLENDIRME } & KISALTMASI \\
\hline ÇOK ZAYIF & VP \\
ZAYIF & $\mathrm{P}$ \\
ORTA DERECEDE ZAYIF & $\mathrm{MP}$ \\
ORTA & $\mathrm{F}$ \\
ORTA DERECEDE İİ & $\mathrm{MG}$ \\
İYI & $\mathrm{G}$ \\
ÇOK IYIİ & $\mathrm{VG}$
\end{tabular}

Tablo 8. Alternatifler ve Kriterler Arasındaki İlişkiyi Gösteren Karar Matrisi

\begin{tabular}{l|c|c|c|c}
\hline KRITERLER & A1 & A2 & A3 & A4 \\
\hline DOZAJLAMA SÜRESİ & G & VG & VG & G \\
\hline HAREKET KABİLIYETİ & F & G & G & G \\
\hline MOTOR GÜCÜ & F & VG & F & F \\
\hline MAMA YAPMA SÜRESI & G & G & G & VG \\
\hline YIKAMA SİSTEMİ & F & F & MG & VP \\
\hline PASTÖRİZE ETME SÜRESİ & VG & G & G & F \\
\hline ÜRÜNÜN FIYATI & P & F & F & G \\
\hline
\end{tabular}




\begin{tabular}{|l|c|c|c|c}
\hline SATIŞ SONRASI HİZMET & G & MP & F & P \\
\hline ÜRÜN TESLIMM SÜRESİ & G & F & F & P \\
\hline DİL SEÇENEĞİ & G & G & G & VG \\
\hline
\end{tabular}

Karar matrisindeki ifadelerin gri sayı karşılı̆̆ için Li ve arkadaşlarının 2007 yılında yaptıkları çalışmadan yararlanılmıştır. İfadelerin gri sayı karşılıkları Tablo 3'te verilmiştir. Gri sayıların durulaştırılmasında eşit ağırlıklı ortalama durulaştırması kullanılmıştır (Köse, vd, 2010).

Karar matrisinin normalize edilmesinde kullanmak üzere referans serisi oluşturulmuştur. Referans serisi her bir kriterin maksimum değeri alınarak bulunmuştur. Karar matrisi ve referans serisi elde edildikten sonra normalizasyon işlemi yapılmıştır. Karar matrisindeki değerin yüksek olması iyi olduğundan, bu işlemin yapılmasında 5. denklem kullanılmıştır. Karar matrisi normalize edildikten sonra her bir değerin istenen değerden uzaklığını veren mutlak değer matrisi oluşturulmuştur. Bu matris oluşturulurken 8. denklem kullanılmıştır.

Gri ilişkisel katsayı matrisinin değerlerinden 3. alternatifin değeri örnek oluşturması açısından aşağıda verilmiştir.

\section{$\gamma_{3 j}=\left\{\begin{array}{llllllllll}1 & 1 & 0,333 & 0,333 & 1 & 0,556 & 0,478 & 0,478 & 0,478 & 0,333\end{array}\right\}$}

Gri ilişkisel derecelerin hesaplanmasında gri ilişkisel katsayı matris değerlerinin kriter ağırlıkları ile çarpılması gerekir. Her bir alternatif için kriterler ağırlıklar ile çarpıldıktan sonra gri ilişkisel dereceler elde edilir. Kriterin eşit öneme sahip olduğu varsayımına göre denklem 10 kullanılmıştır. Toplam 10 kritere göre değerlendirme yapıldığından kriter ağırlığ1 0,10 olarak alınmıştır. Kriter ağırlıklarının farklı olması durumunda ise denklem 11 kullanılır. Burada kriterlerin ağırlıkları AHP yönteminden elde edilmiştir ve aşağıdaki gibidir.

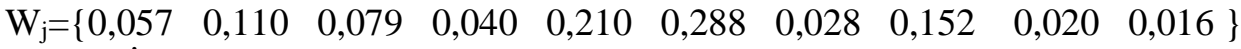

İki yönteme göre bulunan gri ilişkisel dereceler ve alternatiflerin sıralanması Tablo 9'daki gibidir.

Tablo 9. Gri İlişkisel Derecelere Göre Alternatiflerin Sıralanması

\begin{tabular}{|l|c|c|c|c|}
\hline \multirow{2}{*}{ Alternatifler } & \multicolumn{2}{|c|}{$\begin{array}{c}\text { AHP'den alınan kriter ağırlıklarına } \\
\text { göre }\end{array}$} & $\begin{array}{c}\text { Her bir kriterin eşit önemde olduğu } \\
\text { varsayımına göre }\end{array}$ \\
\cline { 2 - 5 } & $\begin{array}{c}\text { Gri ilişkisel } \\
\text { derece }\end{array}$ & Sıralama & $\begin{array}{c}\text { Gri ilişkisel } \\
\text { derece }\end{array}$ & \begin{tabular}{c} 
Sıralama \\
\hline 1.Alternatif
\end{tabular} \\
\hline 2.Alternatif & 0,720 & 1 & 0,571 & 4 \\
\hline 3.Alternatif & 0,659 & 3 & 0,630 & 1 \\
\hline 4.Alternatif & 0,677 & 2 & 0,599 & 3 \\
\hline
\end{tabular}

Tablo 9'a bakıldığında AHP'den alınan kriter ağırlıklarına göre 1. Alternatifin en iyi alternatif olduğu görülmektedir. Eğer 1. Alternatif olan tedarikçi ile beklenmeyen bir problem yaşanırsa, bu durumda işletme 2. en iyi olan 3. Alternatifi seçmelidir. Kriterlerin eşit önemde olduğu düşünüldüğünde ise 2. Alternatif en iyi alternatif gibi görünmektedir. Eşit önem varsayımına göre ise 2. Sirada 4. Alternatif yer almaktadır. AHP'den alınan kriter ağırlıkları ile kriterlerin eşit öneme sahip olma durumları farklı sonuçlar vermiştir. 


\section{SONUÇ}

İşletmelerde birçok alanda karar verme süreci söz konusudur. Karar verme problemleri; değerlendirilmesi gereken kriterleri ve alternatifleri içermektedir. Karar verme aşamasında değerlendirilen kriterlerin her biri eşit ağırlıkta olabileceği gibi yöneticinin gözünde farklı öneme de sahip olabilmektedir. Karar vericilerin çok sayıda alternatif arasından en iyisini seçebilmesi için çok kriterli karar verme metotları geliştirilmiştir. AHP, TOPSİS, Electre, Promethee, Veri Zarflama, Gri İlişsisel Analiz, AAS literatürde en çok kullanılan metotlardan bazılarıdır.

$\mathrm{Bu}$ çalışmada bir işletmenin makine seçimine yardımcı olmak için çok kriterli karar verme metotlarından olan AHP ve GİA yöntemleri bir arada kullanılmıştır. İşletme makine alımı yapabileceği toplam 4 alternatif belirlemiştir. İşletmedeki karar vericilerle yapılan görüşmelerde alternatiflerin seçiminde rol oynayacak toplam 10 kriter belirlenmiştir. 10 kritere bakıldığında hepsinin yöneticinin gözünde eşit öneme sahip olmadığı anlaşılmıştır. $\mathrm{Bu}$ nedenle kriterlerin önem derecelerine bağlı olarak ağırlıklarını veren AHP yöntemi kullanılmıştır. AHP yöntemine göre en önemli kriter 0,288'lik ağırlıkla pastörize etme süresidir. 2. önemli kriter ise 0,210'luk ağırlıkla yıkama sistemidir. Dil seçeneği kriteri ise 0,016 'lık ağırlıkla son sıradadır.

Kriterlerin önem sıralaması AHP yöntemi ile belirlendikten sonra hangi alternatifin hangi kriterde nasıl olduğu ile ilgili bir matris oluşturulmuştur. $\mathrm{Bu}$ matris oluşturulurken işletmedeki karar vericilerin rahatlıkla değerlendirme yapabilmeleri için Tablo 7'deki ifadeleri kullanmaları istenmiştir. Bu matristeki ifadelerin gri sayı karşılıkları verildikten sonra durulaştırma işlemi yapılmış ve GİA uygulanmıştır. AHP'den alınan kriter ağırlıklarına göre hesaplanan gri ilişkisel derecelerde 0,720 ile 1 . Alternatifin seçilmesi gerektiği görülmüștür. Sırasıyla 0,677 ile 3. Alternatif, 0,659 ile 2. Alternatif seçilmelidir. 4. Alternatifin gri ilişkisel derecesi ise 0,463 ile diğer alternatiflere göre çok düşüktür ve sonuncu sıradadır. Kriterlerin eşit öneme sahip olduğu varsayımında ise bu kriterin gri ilişkisel derecesi 0,600'dür ve bu alternatif 2. sırada çıkmıştır. Bunun nedeni 4. Alternatifin daha az önemli olan kriterlerden daha yüksek değer almış olmasından kaynaklanmıştır.

Çalışmanın sonuçları işletmedeki karar vericiler ile paylaşılmıştır. $\mathrm{Bu}$ çalışmadaki kriterler işletme karar vericileri tarafından belirlenmiştir. Literatürde makine alım problemlerinde farklı kriterlerin oluşturulduğu bilinmektedir. Kriterlerin belirlenmesinde işletmeye çok fazla müdahale edilmemiştir. Sonraki çalışmalarda işletmenin kriterleri ana kriter başlıkları altında toplanarak bu kriterlerin alt kriter olarak değerlendirilmesi yapılabilir. Kriterler arası ilişkiler değerlendirilerek kriter ağırlıklarının hesaplanmasında bir hiyerarşiye bağlı kalmaktansa bir ăg yapısı kullanılmasına izin veren analitik ağ prosesi kullanılabilir. Ayrıca alternatiflerin sıralanması için TOPSIS gibi farklı çok kriterleri karar yöntemleri de kullanılabilir. 


\section{KAYNAKÇA}

Arslan, R., Bircan, H., Arslan Ö., (2017), Tekstil Firmalarında Finansal Performansın Analitik Hiyerarşi Prosesi İle Ağırlıklandırılmış Gri İlişkisel Analiz Yöntemiyle Değerlendirilmesi, Kahramanmaraş Sütçü İmam Üniversitesi İktisadi ve İdari Bilimler Dergisi, Cilt:7, Say1:2, ss: 19-36.

Çakır, E.,Akar, S., (2017),Bütünleşik Swara-Topsis Yöntemi ile Makine Seçimi: Bir Üretim İşletmesinde Uygulama, International Journal of Academic Value Studies, Vol: 3, Issue: 13 , pp. 206-216

Ecemiş, O., ve Yaykaşl1, M., (2018), Çok Kriterli Karar Verme Yöntemleriyle Sürdürülebilir Tedarikçi Seçimi Ve Bir Uygulama, Akademik Sosyal Araştırmalar Dergisi, Yı1: 6, Sayı: 83,ss:382-399.

Korucuk, S., (2018), Soğuk Zincir Taşımacılı̆̆ Örneği, Iğdır Üniversitesi Sosyal Bilimler Dergisi Say1: 16, ss:341-365.

Köse, E., Erol, S., Temiz, İ. (2010). Grey System Approach For EOQ Models. Sigma, 28, 298-309.

Kuo, Y., Yang, T., \& Huang, G. W. (2008). The use of grey relational analysis in solving multiple attribute decision-making problems. Computers \& industrial engineering, 55(1), 80-93.

Lee, W. S., \& Lin, Y. C. (2011). Evaluating and ranking energy performance of office buildings using Grey relational analysis. Energy, 36(5), 2551-2556.

Li, G. D., Yamaguchi, D., \& Nagai, M. (2007). A grey-based decision-making approach to the supplier selection problem. Mathematical and computer modelling, 46(3-4), 573-581.

Organ, A. ve Yalçın, E., (2017), “ An Integrated Approach Based on Fuzzy Ahp andGrey Relational Analysis for Heating Source Selection, European Scientific Journal May, ss:221-232.

Pancaroğlu, M., S., (2018), Akıllı Telefon Seçim Faktörlerinin Bütünleşik Yapısal Eşitlik Modeli Analitik Hiyerarşi Süreci ile İncelenmesi, Karadeniz Teknik Üniversitesi, SBE, Yüksek Lisans tezi.

Pophali, G. R., Chelani, A. B., Dhodapkar. R. S., (2011)."Optimal selection of full scale tannery effluent treatment alternative using integrated AHP and GRA approach."Expert Systems with Applications 38.9 : 10889-10895

Saaty, T. (1986), Axiomatic Foundation of the Analytic Hierarchy Process, Management Science; V: $32 ; \mathrm{N}: 7 ; \mathrm{ss}: 841-855$

Saaty, T. L. (2005). Theory and applications of the analytic network process: Decision making with benefits, opportunities, costs, and risks. Pittsburgh: RWS Publications.

Said, F.S., Harputlugil, T., (2019), A Research on Selecting the Green Building Certification System Suitable for Turkey, GRID - Mimarlik Planlama ve Tasartm Dergisi, Cilt:2, Sayı:1, ss:2553.

Samvedi, A., Jain V., Chan, T., S., (2012), An integrated approach for machine tool selection using fuzzy analytical hierarchy process and greyrelational analysis, International Journal of Production Research, Vol:50, No:12, pp:3211-3221.

Senger, Ö., \& Albayrak, Ö. K. (2016). Gri İlişki Analizi Yöntemi İle Personel Değerlendirme Üzerine Bir Çalışma.Uluslararası İktisadi ve İdari İncelemeler Dergisi,Cilt:9, Sayı:17, ss:235-258.

Şahin, Y. ve Aydemir, E., (2019), Ak1llı Telefon Teknik Özellik Önem Derecelerinin AHP Ağırlıklı Gri İlişkisel Analiz Yöntemi ile Belirlenmesi, Eskişehir Osmangazi Üniversitesi IIBFF Dergisi, C. 14, S. 1,ss: 225 - 238.

Şahin, Y. ve İpek, Ç., (2018), Ahp Temelli Gri İlişkisel Analiz Yöntemi ile Konut Seçimi, Gümüşane Üniversitesi sosyal Bilimler Enstitüsü Dergisi, Cilt:9, Say1:25, ss:153-172.

Şeker, A., Yurdakul, M., (2014), Bulanık Çok Kriterli Karar Verme Yöntemlerinin Alışılmamış İmalat Yöntemlerinin Seçiminde Kullanılması, Journal of the Faculty of Engineering and Architecture of Gazi University Cilt 29, No 3, 589-603, 2014 Vol 29, No 3, ss:589-603

Tayyar, N., Akcanlı, F., Genç, E., Erem, I., (2014), BİST'e Kayıtlı Bilişim ve Teknoloji Alanında Faaliyet Gösterenİşletmelerin Finansal Performanslarının Analitik HiyerarşiProsesi (AHP) ve Gri İlişkisel Analiz (GİA) YöntemiyleDeğerlendirilmesi, Muhasebe ve Finansman Dergisi, Ocak sayıs1, ss:19-40. 
Türkbey, O. (2003). Çok Amaçlı Makina Sıralama Problemi İçin Bir Bulanık Güçlü Metod. Dokuz Eylül Üniversitesi Mühendislik Fakültesi Fen ve Mühendislik Dergisi, 5(3), 81-98.

Wang, Z., Lei, T., Chang, X., Shi, X., Xiao, J., Li, Z., He, X., Zhu, J., Yang, S., (2015). "Optimization of a biomass briquette fuel system based on grey relational analysis and analytic hierarchy process: a study using cornstalks in China Applied Energy"157: 523532

Xiao, X. C., Wang, X. Q., Fu, K. Y., \& Zhao, Y. J. (2012). Grey relational analysis on factors of the quality of web service. Physics Procedia, 33, 1992-1998.

\section{SUMMARY}

Decision-making problem includes criteria and alternatives to be evaluated so it has always been difficult for managers in an extremely competitive world. One of the important problems for decision makers is machine selection. During machine selection, decision makers have to choose the best machine among many alternatives considering many criteria. These criteria may have different significance in the eyes of the manager or decision maker. Multi Criteria Decision Making Methods can be used in many areas when decision making process is weighted on the basis of many influential parameters. In the literature, it is seen that different multi criteria decision making methods are used in decision making problems in different fields.

In this study, it is aimed to help the machine selection problem of a particular manufacturing company which buys and sells farm equipment and agricultural machinery and also makes milk production. Managers have to give the optimum decision and choose the best machine among different alternatives. The company identified a total of four alternatives to purchase a machine. During the interviews with the decision-makers in the enterprise, a total of ten criteria were determined to play a role in the selection of alternatives. Looking at the ten criteria, it was found that not all of them have equal importance in the eyes of the manager. For this reason, the AHP method, which gives weight according to the importance of the criteria, is used.

When we look at the weights of the criteria estimated by using AHP method considering the decision makers' subjective judgments; the most important criteria is defined as pasteurization time and second one is defined as washing system. Language selection criteria is in the last place with lowest weight. Considering these criteria weights, Grey Relational Analysis is used to select the most suitable alternative. It is determined that giving different weight values to the criteria, which produced more realistic solutions when it is considered that decision making priorities should be taken into account and so AHP and grey relational analysis methods are used together Additionally, we wanted to see the results when we used equal weights to each criteria and it seemed that in equal weighted scenario, the results changed.

As a result of the analysis, made by considering the importance given to the criteria, alternatives are ranked and the best alternative to buy the machine is also shared with the company manager and other decision makers. 